\title{
Retraction Note to: Efficacy of Menatetrenone (Vitamin K2) against Non-Vertebral and Hip Fractures in Patients with Neurological Diseases
}

\section{Meta-Analysis of Three Randomized, Controlled Trials}

Jun Iwamoto $^{1} \cdot$ Hideo Matsumoto $^{1} \cdot$ Tsuyoshi Takeda $^{1}$

Published online: 26 March 2018

(C) Springer International Publishing AG, part of Springer Nature 2018

Retraction to: Clin Drug Investig 2009; 29(7):471-479

https://doi.org/10.2165/00044011-200929070-00005

The Editor-in-Chief has retracted this article because two of the three studies [1,2] included in the meta-analysis (cited as references 11 and 12) have been retracted due to fabrication of the data, which has rendered the results of this meta-analysis invalid.

All authors agreed to this retraction.

\section{References}

1. Sato Y, Kanoko T, Satoh K, et al. Menatetrenone and vitamin D2 with calcium supplements prevent nonvertebral fracture in elderly women with Alzheimer's disease. Bone. 2005;36:61-8. https://doi. org/10.1016/j.bone.2004.09.018.

2. Sato Y, Honda Y, Kaji M, et al. Amelioration of osteoporosis by menatetrenone in elderly female Parkinson's disease patients with vitamin D deficiency. Bone. 2002;31:114-8. https://doi.org/10. 1016/S8756-3282(02)00783-4.

The original article can be found online at https://doi.org/10.2165/ 00044011-200929070-00005.

\footnotetext{
Jun Iwamoto

jiwamoto@sc.itc.keio.ac.jp

1 Institute for Integrated Sports Medicine, Keio University

School of Medicine, Tokyo, Japan
} 